\title{
Simulation techniques in the anatomy curriculum: review of literature
}

\author{
K. Torres ${ }^{1}$, A. Torres ${ }^{2}$, Ł. Pietrzyk ${ }^{1}$, J. Lisiecka², M. Błoński ${ }^{3}$, M. Bącik-Donica ${ }^{2}$, \\ G. Staśkiewicz ${ }^{2}$ R. Maciejewski \\ ${ }^{1}$ Laboratory of Medical Simulation, Medical University of Lublin, Poland \\ ${ }^{2}$ Human Anatomy Department, Medical University of Lublin, Poland \\ ${ }^{3}$ Department of Anaesthesiology and Intensive Care, District Specialist Hospital, Lublin, Poland \\ [Received 16 July 2013; Accepted 23 August 2013]
}

\begin{abstract}
Modern medical education faces a problem of combining the latest technology, procedures and information with classic teaching methods. Simulation is a technique, which replaces or amplifies doctor-patient experiences in controlled conditions and therefore evokes or replicates substantial aspects of the real world in a fully interactive manner. The basic course of anatomy in medical education could be recognised as the best example of implementing new educational techniques such as simulation, into the traditional medical curriculum. The PubMed database was searched using specific key words. Finally 72 articles were accepted and were divided into 3 basic categories of teaching methods: Category 1 - cadaveric dissection, Category 2 - simulator based education and Category 3 - other. A state of the art anatomical curriculum offers numerous possibilities and solutions including the oldest like cadaveric dissection and newest like simulators. Different simulation techniques are used with different intensity; however cadaveric dissection is still the most popular method. The second most frequent method is simulation-based training, in which North America is the leading country. The identification of anatomical structures during virtual surgical procedures or laparoscopic robotic procedures can be integrated into the traditional anatomy course. New technologies are supportive and beneficial in anatomy teaching however each excitement of new technologies sometimes should be tempered and evaluated for its usefulness in making the learning process constructive for students and their future practice. (Folia Morphol 2014; 73, 1: 1-6)
\end{abstract}

Key words: anatomy, simulation, cadaver, dissection, medical students

\section{INTRODUCTION}

Modern medical education faces a problem of combining the latest technology, procedures and information with classic teaching methods. The goal is to prepare students to become physicians equipped with the latest conceptions in medicine. Another challenge is the linking of theoretical and practical knowledge without forgetting the socio-practical aspect of medical care. Training, from the very beginning, taking place in a reality-reflected environment (e.g. simulation-based training) seems to be a beneficial solution.

Simulation is a technique, which replaces or amplifies doctor-patient experiences in controlled conditions and therefore evokes or replicates substantial aspects of the real world in a fully interactive manner [20]. Simulation techniques improve both cognitive and practical aspects of the education process in predictable and stress free conditions. 
Table 1. Number of articles divided in three studied categories

\begin{tabular}{lccc}
\hline & $\begin{array}{c}\text { Category 1. } \\
\text { Cadaveric dissection }\end{array}$ & $\begin{array}{c}\text { Category 2. } \\
\text { Simulator based education }\end{array}$ & $\begin{array}{c}\text { Category } 3 . \\
\text { Other }\end{array}$ \\
\hline Europe & 25 & 1 & 7 \\
North America & 11 & 6 & 9 \\
South America & 1 & - & - \\
Asia & 5 & - & 3 \\
Australia & 2 & - & 2 \\
Total & 44 & 7 & 21 \\
\hline
\end{tabular}

The basic course of anatomy in medical education could be recognised as the best example of implementing new educational techniques such as simulation, into the traditional medical curriculum. According to the Association of American Medical Colleges (AAMC) survey, $84 \%$ of medical schools during the first year and $91 \%$ during the second year declared usage of simulation techniques in clinical skills and physical diagnosis teachings. Moreover, 86 of 90 participating medical schools reported the usage of simulation elements in the preclinical courses and $45 \%$ declared its usage in anatomy teachings [36].

The aim of the study was to present various teaching methods in the education of anatomy by reviewing literature using the PubMed database.

The PubMed database was searched in September 2012 using the key words: 'medical simulation anatomical education'; 'pre-clinical medical simulation'; 'medical simulation education'; 'medical simulation in anatomy'; 'medical simulation visualisation student education'; 'medical simulation cadaver education'; 'simulation-based medical teaching and learning'; 'anatomy curriculum undergraduate medical students'; and 'anatomy curriculum preclinical students surgery'. For further work only full articles fulfilling the criteria such as: 'medical students'; 'preclinical students'; or 'anatomy education' were studied.

The initial search produced 9,287 results from which 1,454 papers were selected. The second reviewing excluded 1,382 papers. Finally 72 articles were accepted and were divided into three basic categories of teaching methods: Category 1 - cadaveric dissection, Category 2 - simulator based education and Category 3 - other.

\section{TEACHING TECHNIQUES}

Different simulation techniques are used with different intensity; however cadaveric dissection is still the most popular method. The second most frequent method is simulation-based training, in which North America is the leading country. The number of articles reporting the three studied categories of teaching methods is presented in Table 1.

\section{Category 1. Cadaveric dissection}

The role of the classical educational method in the curriculum of anatomy has changed nowadays. The students' role has changed from passive observers to active participants, who want to know more than 'where is it' or 'what is it relation to other structures'. The main aim of cadaveric dissection is to show that anatomical knowledge can be useful in the practice of real medicine.

Academics highlight the fact that dissection may impart anatomical knowledge as well as offer other relevant, positive learning opportunities to enhance skills and attitude of future physicians [28]. Specifically, the anatomy course has a strong emotional influence on young people who want to be physicians. Knowledge and skills like: teamwork, stress coping strategies, empathy, respect for the human body, theory and practice integration with preparation for clinical studies are taught during the dissection course $[9,28]$.

It has been reported that during undergraduate medical education, the trainee should not only gain theoretical knowledge but also acquire essential skills [39]. What is more, the students' interest rate level in studying anatomy increased substantially when the clinical aspects were introduced into the course [25]. Clinical cadaveric anatomy seems to be helpful to the surgeons [4]. The surgical procedures shown to the undergraduates provide a purposeful and memorable way of learning anatomy, in comparison with conventional teaching methods [34]. In most of the surgical-based anatomy curricula the clinically relevant procedures on cadavers were shown and different surgical procedures like pancreaticoduodenectomy or 
shoulder hemi-arthroplasty were performed with or without a student's help $[3,34]$. Some programs go one step further and teach preclinical students how to behave in a sterile surgical environment [10]. In other programs pathological conditions, e.g. pleural or pericardial effusions, were simulated and treated. According to Wilson and Nava [52] collaborative dialogue between Departments of Anatomy and Surgery is significant. Thanks to this cooperation, medical students get to know the patient's history, the medical procedures being performed during the treatment process and it makes them more interested in the anatomy course.

Another way to improve anatomical curriculum is to make laboratory time more interesting and to encourage discussion. Some universities create specially designed aim-focused tasks which are given to students during dissection. These tasks were assigned to students throughout dissection or built dissection teams which aim is to identify lists of structures given on the day of dissection $[22,26]$.

The cadaveric specimens may be replaced by the plastinated prosections. This technique shows with details all structures and relations between them [19]. The last branch of modern anatomical curriculum is radiological anatomy using images based on cadavers. The leaders of this procedure claimed that radiological images show anatomical structures in multiple planes and may be effective in the teaching of anatomical spatial relationships, which happens to be the most difficult for students [30]. This tool not only enables the scanning of the whole body but also creates virtual patient imaging and develops interactive simulation programs for clinical practice [47].

\section{Category 2. Simulator based education}

According to the AAMC survey, simulation is probably the most prominent innovation in medical education over the past 15 years [36]. Simulators used in the teaching of anatomy may be classified into different categories. The division depends on the level of reality, partial or holistic view on human"s body or interactions with surroundings [31, 42]. An example of these are the high-fidelity parts of the body manikins with very basic application to demonstrate or indicate anatomical structures and the Human Patient Simulator which is one of the most impressive high-fidelity whole body manikins $[2,43]$.

Simulators may assist in preclinical medical skills, teaching to enhance the knowledge and increase experience. Training in surgical procedures during anatomical classes should become the basic objective of the anatomy curriculum. The identification of anatomical structures during virtual surgical procedures or laparoscopic robotic procedures can be integrated into the traditional anatomy course $[21,41,53]$.

\section{Category 3. Other (problem-based learning and visualisation)}

One of the integrating methods of anatomical knowledge with clinical information and skills is the course with problem-based learning (PBL). This method uses different techniques, e.g.: classical clinical PBL, clinical cases for medical students based on computed tomography scans, real patient clinical cases based on real patients' problems or documented case presentation of the tutorials in the form of patient/physician history taking and physical examination videos [11, 14, 15, 46, 49]. However, the interactive lectures seem to be the most sophisticated variants of the PBL method during which small-group tutorial sessions are integrated into each anatomical section and use anatomical models, bones, radiographs, and interactive 3-dimensional (3D) images [18].

Interactive programs visualising anatomy are becoming more popular. Implementation of radiology basics and new learning opportunities involving such techniques as image labelling, 3D reconstruction, and multiplanar reformatting appear to be relevant [48]. The virtual human dissector or the 3D stereoscopic images are significant elements of the modern anatomical curriculum making the study of anatomy more effective $[12,16,35,40]$.

The number of hours of anatomy in the medical curricula decreases systematically. Drake et al. [17] estimated that the mean number of total course hours was 149 while for lectures it was 43 and for laboratories 94. To compare, in 1966 it was almost $300 \mathrm{~h}$ of gross anatomy course while 7 years later it was $100 \mathrm{~h}$ less $[8,24]$. The next problem is the reduction of medically qualified anatomy teachers which has an influence on the teaching process [49]. All of these components factor into the opinions that low levels of anatomical knowledge amongst medical students are not enough for a good education and for the safety of patients [51].

It seems to be obvious that the aim of educating medical students is to teach them knowledge and skills. However, this process depends on both, student and teachers. To eliminate mistakes and also standardise the teaching process universities introduced clinical 
skills laboratories or centres of Objective Structured Clinical Examination [1, 29, 38].

What is more, expectations from doctors even those that have recently graduated are still rising, however according to the classical study program students are not being taught technical skills, leadership, team work, communication skills, situation awareness, and decision-making skills [1]. The best option for this situation seems to be well-prepared and long-lasting medical simulation training.

The next problem is the psychological aspect and the applicative skills in the medical curriculum. Swick [45] reported that it is crucial to introduce the elements of professionalism starting from basic science courses, especially anatomy, as well as in clinical sciences. Similar observations were made by Swartz [44], who postulated the need for introducing, monitoring and evaluating the aspects of professionalism from the very beginning the first semester of medical school. According to the author, the best place for this is the "Gross Anatomy" course, during which students spent a lot of time with teachers who are professionals in their fields and may spread this wisdom and way of being to theirs students.

Dissection seems to be present in the anatomy curriculum from the beginning. However, cadaveric dissections have some limitations such as those connected with cadavers like colour, smell, inability to change the position or being auscultated and connected with ethics and legacy [32]. That is why simulation techniques seem to be helpful and partially may replace the cadavers.

In the future, the anatomy curriculum will be connected with increasing number of modern technologies such as audio-video, multi-stimuli PBL or visualisation techniques to give the best results. The best example of a combination of these technologies is the Surgical Anatomy Course (SAC) created by Surgeons and Faculty Members from the Human Anatomy Department of Medical University of Lublin. SAC consists of $12 \mathrm{~h}$ of classes divided into 4 modules ( $3 \mathrm{~h}$ each). Every module consists of a problem-based lecture, simulation-based training and cadaveric dissections. Classes describe 4 topics: Module A: surgical anatomy of liver and bile ducts; Module B: anatomy of the anterolateral abdominal wall; Module C: anatomy of the gastrointestinal tract, and Module D: presenting anatomy of the pelvis.

According to the Accreditation Council on Graduate Medical Education there are 6 core competencies: patient care, medical knowledge, interpersonal and communication skills, professionalism, practice-based learning and systems-based practice. Programs of medical studies and residency should be constructed based on these issues [13]. That is why simulation techniques for postgraduate doctors are adequate and necessary to improve competencies. Simulation can be used in training medical procedures, improve doctor-patient communication and teamwork skills to reduce medical mistakes and protect patients [23].

It can be simulation-based laparoscopic training program for surgeons and as well as training in lumbar puncture or central venous catheter insertion for internal medicine and emergency medicine residents [6, 7, 33].

A state of the art anatomical curriculum offers numerous possibilities and solutions including the oldest like cadaveric dissection and newest like simulators. Patel and Moxham [37] observed that the professional anatomical dissection is the most suitable method to achieve good anatomical learning outcomes. Similar opinion were expressed by Kerby et al. [27] claiming that dissection should remain a leading teaching method in modern anatomy courses in medical schools. Azer and Eizenberg [5] demonstrated that students reported that dissection increased understanding of anatomical structures, provided them with a 3D perspective and helped them recall what they learnt. On the other hand, there are publications indicating that videos or clinical PBL improved the quality of the anatomy course $[14,50]$.

\section{CONCLUSIONS}

To conclude it can be said that new technologies are supportive and beneficial in anatomy teaching however each excitement of new technologies sometimes should be tempered and evaluated for its usefulness in making the learning process constructive for students and their future practice.

\section{REFERENCES}

1. Akaike $M$, Fukutomi $M$, Nagamune $M$, Fujimoto $A$, Tsuji $A$, Ishida K, Iwata T (2012) Simulation-based medical education in clinical skills laboratory. J Med Invest, 59: 28-35.

2. Al-Elq AH (2010) Simulation-based medical teaching and learning. J Family Community Med, 17: 35-40.

3. Are C, Stoddard HA, Northam LC, Thompson JS, Todd GL (2009) An experience in surgical anatomy to provide first-year medical students with an early exposure to general surgery: a pilot study. J Surg Educ, 66: 186-189.

4. Are C, Stoddard HA, Thompson JS, Tood GL (2010) The influence of surgical demonstrations during an anatomy course on the perceptions of first-year medical students toward surgeons and a surgical career. J Surg Educ, 67: 320-324. 
5. Azer SA, Eizenberg N (2007) Do we need dissection in an integrated problem-based learning medical course? Perceptions of first- and second-year students. Surg Radiol Anat, 29: 173-180.

6. Barsuk JH, Cohen ER, Caprio T, McGaghie WC, Simuni T, Wayne DB (2012) Simulation-based education with mastery learning improves residents' lumbar puncture skills. Neurology, 79: 132-137.

7. Barsuk JH, McGaghie WC, Cohen ER, O'Leary KJ, Wayne DB (2009) Simulation-based mastery learning reduces complications during central venous catheter insertion in a medical intensive care unit. Crit Care Med, 37: 2697-2701.

8. Blevins CE, Cahill DR (1973) Gross anatomy: current courses, training programs, and prospective needs. J Med Educ, 48: 264-270.

9. Böckers A, Jerg-Bretzke L, Lamp C, Brinkmann A, Traue HC, Böckers TM (2010) The gross anatomy course: an analysis of its importance. Anat Sci Educ, 3: 3-11.

10. Boeckers A, Fassnacht U, Boeckers TM (2008) "Theatrum anatomicum": a revived teaching facility in gross anatomy. Ann Anat, 190: 495-501.

11. Bohl M, Francois W, Gest T (2011) Self-guided clinical cases for medical students based on postmortem CT scans of cadavers. Clin Anat, 24: 655-663.

12. Brown PM, Hamilton NM, Denison AR (2012) A novel 3D stereoscopic anatomy tutorial. Clin Teach, 9: 50-53.

13. Council on Graduate Medical Education (1997) "Preparing Learners for Practice in a Managed Care Environment". Health Resources and Services Administration, Washington.

14. DiLullo C, Coughlin P, D'Angelo M, McGuinness M, Bandle J, Slotkin EM, Shainker SA, Wenger C, Berray SJ (2006) Anatomy in a new curriculum: facilitating the learning of gross anatomy using web access streaming dissection videos. J Vis Commun Med, 29: 99-108.

15. DiLullo C, Morris HJ, Kriebel RM (2009) Clinical competencies and the basic sciences: an online case tutorial paradigm for delivery of integrated clinical and basic science content. Anat Sci Educ, 2: 238-243.

16. Donnelly L, Patten D, White P, Finn G (2009). Virtual human dissector as a learning tool for studying cross-sectional anatomy. Med Teach, 31: 553-555.

17. Drake RL, McBride JM, Lachman N, Pawlina W (2009) Medical education in the anatomical sciences: the winds of change continue to blow. Anat Sci Educ, 2: 253-259.

18. Evans DJ, Watt DJ (2005) Provision of anatomical teaching in a new British medical school: getting the right mix. Anat Rec B New Anat, 284: 22-27.

19. Fruhstorfer BH, Palmer J, Brydges S, Abrahams PH (2001) The use of plastinated prosections for teaching anatomy: the view of medical students on the value of this learning resource. Clin Anat, 24: 246-252.

20. Gaba D (2004) The future vision of simulation in health care. Qual Saf Health Care, 13 (suppl. 1): i2-i10.

21. Hariri S, Rawn C, Srivastava S, Youngblood P, Ladd A (2004) Evaluation of a surgical simulator for learning clinical anatomy. Med Educ, 38: 896-902.

22. Hofer RE, Nikolaus OB, Pawlina W (2001) Using checklists in a gross anatomy laboratory improves learning outcomes and dissection quality. Anat Sci Educ, 4: 249-255.

23. Issenberg SB, Chung HS, Devine LA (2011) Patient safety training simulations based on competency criteria of the
Accreditation Council for Graduate Medical Education. Mt Sinai J Med, 78: 842-853.

24. Kahn RH, Alden RH, Bennett HS, Bridgman CF, Greulich RC, Leblond CP, Matzke HA, Schmidt AJ, Sidman RL, Singer R (1966) Curriculum, faculty, and training in anatomy. Educational Affairs Committee, American Association of Anatomists. J Med Educ, 41: 956-964.

25. Kanchan H. Rao, R. Harsha Rao (2009) Perspectives in Medical Education 8. Enhancing Preclinical Education in Japan with a Clinically Focused, Interactive Anatomy Curriculum. Keio J Med, 58: 210-215.

26. Kang SH, Shin JS, Hwang YI (2012) The use of specially designed tasks to enhance student interest in the cadaver dissection laboratory. Anat Sci Educ, 5: 76-82.

27. Kerby J, Shukur ZN, Shalhoub J (2011) The relationships between learning outcomes and methods of teaching anatomy as perceived by medical students. Clin Anat, 24: 489-497.

28. Lempp HK (2005) Perceptions of dissection by students in one medical school: beyond learning about anatomy. A qualitative study. Med Educ, 39: 318-325.

29. Lofaso DP, DeBlieux PM, DiCarlo RP, Hilton C, Yang T, Chauvin SW (2011) Design and effectiveness of a required pre-clinical simulation-based curriculum for fundamental clinical skills and procedures. Med Educ Online, 16.

30. Lufler RS, Zumwalt AC, Romney CA, Hoagland TM (2010) Incorporating radiology into medical gross anatomy: does the use of cadaver CT scans improve students' academic performance in anatomy? Anat Sci Educ, 3: 56-63.

31. Maran NJ, Glavin RJ (2003) Low-to high-fidelity simulation: a continuum of medical education? Med Edu, 37: 22-28.

32. McLachlan JC (2004) New path for teaching anatomy: living anatomy and medical imaging vs. dissection. Anat Rec B New Anat, 281: 4-5.

33. Nugent E, Shirilla N, Hafeez A, O'Riordain DS, Traynor O, Harrison AM, Neary P (2013) Development and evaluation of a simulator-based laparoscopic training program for surgical novices. Surg Endosc, 27: 214-221.

34. Nutt J, Mehdian R, Parkin I, Dent J, Kellett C (2012) Cadaveric surgery: a novel approach to teaching clinical anatomy. Clin Teach, 9: 148-151.

35. O'Byrne PJ, Patry A, Carnegie JA (2008) The development of interactive online learning tools for the study of anatomy. Med Teach, 30: e260-e271.

36. Passiment M, Sacks H, Huang G (2001) Medical Simulation in Medical Education. Results of an AAMC Survey. Association of American Medical Colleges; https://www. aamc.org/download/259760/data/.

37. Patel KM, Moxham BJ (2008) The relationships between learning outcomes and methods of teaching anatomy as perceived by professional anatomists. Clin Anat, 21: 182-189.

38. Pernar LI, Shaw TJ, Pozner CN, Vogelgesang KR, Lacroix SE, Gandhi TK, Peyre SE (2012) Using an Objective Structured Clinical Examination to test adherence to Joint Commission National Patient Safety Goal--associated behaviors. Jt Comm J Qual Patient Saf, 38: 414-418.

39. Rüsseler M, Weber R, Braunbeck $A$, Flaig W; Lehrteam des Zentrum Chirurgie, Marzi I, Walcher F (2010) Training of practical clinical skills in surgery: a training concept for medical students. Zentralbl Chir, 135: 249-256. 
40. Saxena V, Natarajan P, O'Sullivan PS, Jain S (2008) Effect of the use of instructional anatomy videos on student performance. Anat Sci Educ, 1: 159-165.

41. Seixas-Mikelus SA, Adal A, Kesavadas T, Baheti A, Srimathveeravalli G, Hussain A, Chandrasekhar R, Wilding GE, Guru KA (2010) Can image-based virtual reality help teach anatomy? J Endourol, 24: 629-634.

42. Seropian MA, Brown K, Gavilanes JS, Driggers B (2004) Simulation: not just a Manikin. J Nurs Educ, 43: 164-169.

43. Solyar A, Cuellar H, Sadoughi B, Olson TR, Fried MP (2008) endoscopic sinus surgery simulator as a teaching tool for anatomy education. Am J Surg, 196: 120-124.

44. Swartz WJ (2006) Using gross anatomy to teach and assess professionalism in the first year of medical school. Clin Anat, 19: 437-441.

45. Swick HM (2006) Medical professionalism and the clinical anatomist. Clin Anat, 19: 393-402.

46. Takkunen M, Turpeinen $\mathrm{H}$, Viisanen $\mathrm{H}$, Wigren HK, Aarnio M, Pitkäniemi J (2011) Introduction of real patients into problem-based learning in preclinical first-year anatomy curriculum. Med Teach, 33: 854-856.
47. Tang L, Chung MS, Liu Q, Shin DS (2010) Advanced features of whole body sectioned images: Virtual Chinese Human. Clin Anat, 23: 523-529.

48. Turmezei TD, Tam MD, Loughna S (2009) A survey of medical students on the impact of a new digital imaging library in the dissection room. Clin Anat, 22: 761-769.

49. Turney BW, Gill J, Morris JF (2001) Surgical trainees as anatomy demonstrators: revisited. Ann R Coll Surg Engl, 83 (suppl.): 193-195.

50. Wang J, Zhang W, Qin L, Zhao J, Zhang S, Gu J, Zhou C (2010) Problem-based learning in regional anatomy education at Peking University. Anat Sci Educ, 3: 121-126.

51. Waterston SW, Stewart IJ (2005) Survey of clinicians' attitudes to the anatomical teaching and knowledge of medical students. Clin Anat, 18: 380-384.

52. Wilson DR, Nava PB (2010) Medical student responses to clinical procedure teaching in the anatomy lab. Clin Teach, 7: 14-18.

53. Zaid H, Ward D, Sammann A, Tendick F, Topp KS, Maa J (2010) Integrating surgical skills education into the anatomy laboratory. J Surg Res, 158: 36-42. 